\title{
Use of Management Information Systems Impact on Decision Support Capabilities: A Conceptual Model
}

\author{
Ahmed Abdulatef Mashli Aina, Wang Hu, Al-Nakib Noofal Ahmed Mohsen Mohammed \\ School of Management, Wuhan University of Technology, Wuhan, China
}

\begin{tabular}{|c|c|}
\hline & ABSTRACT \\
\hline $\begin{array}{l}2016 \text { Research Leap/Inovatus Services Ltd. } \\
\text { All rights reserved. } \\
\text { DOI: } 10.18775 / \text { jibrm.1849-8558.2015.14.3004 } \\
\text { URL: } \text { http://dx.doi.org/10.18775/jibrm.1849- } \\
\text { 8558.2015.14.3004 }\end{array}$ & $\begin{array}{l}\text { In this article, the identification and the analysis of the problem in facilitating the role } \\
\text { management information systems have been studied. Moreover, the decision maker's } \\
\text { satisfaction and content of information and information access quality have been critically } \\
\text { analyzed and studied following the methodology of the previous studies. We identified } \\
\text { necessary variables aiming to analyze the influence of management information systems in } \\
\text { decision support capabilities. Precisely, this investigation proposes different hypotheses most of }\end{array}$ \\
\hline $\begin{array}{l}\text { Keywords: } \\
\text { MIS } \\
\text { Information access } \\
\text { Information quality }\end{array}$ & $\begin{array}{l}\text { which aims to identify the relationship between management information systems and decision } \\
\text { support capabilities. The variables included in the research model are the impact on problem } \\
\text { definition, speed of problem identification, decision-making analysis, user satisfaction, } \\
\text { information access, the content of information quality, decision speed, and decision quality. }\end{array}$ \\
\hline
\end{tabular}

Decision making

Decision quality

\section{Introduction}

Decision-making capabilities are becoming popular in all spheres of operations. Due to the advances in the technological areas of the century, most of the businesses, which aim for the success in future, are turning traditional way of doing business into the modern area. Today, successful operation of the firm is not only limited by its ability to produce the products that consumers demand, but also reaching right and important decisions that are vital for the future stability and prosperity of the business. Therefore, most businesses are turning into the automated process of decision-making capabilities in order to ensure the reliability and suitability of the decisions with company goals. Particularly, it is worth to mention the increasing usage of management information systems in this case. Management information systems are reported to be beneficial for the operations of the company from different perspectives. One of the obvious benefits of management information systems is observed in terms of their contribution in decision-making process. Many studies have discovered positive relationship while analyzing the impact of management information systems in decision-making process. Management information systems are believed to foster the process of decision-making capabilities. The review of the previous literature shows the evidence of various studies in support of management of information systems in contributing to the role of decision-making capabilities.
However, most of the paper lacks in identifying the critical importance of information speed and its quality in supporting the role of decision-making capabilities. The identification and the analysis of the problem in facilitating the role of management information systems have not been studied to a greater extent. Moreover, the decision maker's satisfaction and content of information and information access quality have not been critically analyzed and studied. Thus, following the methodology of the previous studies and identifying necessary variables, the current study aims to analyze the influence of management information systems in decision support capabilities. Precisely, this investigation proposes different hypotheses most of which aims to identify the relationship between management information systems and decision support capabilities through different variables. Some of the variables include as proposed in research model are the impact on problem definition, speed of problem identification, decision-making analysis, user satisfaction, information access, the content of information quality, decision speed, and decision quality. The analyses of management information systems are crucial for the short and long term projects of the company. Thus, some important implications are to be taken into account. 


\section{Conceptual Model Construction}

De Lone and McLean (1992) identified different factors influencing the success of Management information system in ensuring the success of decision support systems including system quality, quality of information, the satisfaction of the user, and impact of the individual. Management information systems are reported to have a number of benefits in relation to the support which they provide for enhancing the activities of decision support systems. The main role of management information systems begins from the definition of the problem on to which later stages of actions are based on. Mintzberg (1976) mentioned two important areas in problem definition phase. One of these areas, known as "decision recognition" is believed to start the process of decision support by revealing relevant problems, threats and etc. As to the second phase, known as "diagnosis", is mainly concerned with the analysis and reviews of the previously defined problem and threat in "decision recognition" sphere. This is a crucial aspect of operation in management information systems. The role of management information systems is even becoming vital in capturing and storing information for decision-making purposes. In this case, information may be obtained from different sources including internal and external. Therefore, available information is crucial for identifying problems and threats and further opportunities as well. To be more precise, the information may be defined and analyzed in relation to political, legal, economic, technological and social factors which are considered to be crucial in analyzing changing consumer behavior and market environment. Information is considered to a paly important role in every organization. The use and application of information are significantly related to its value. Most of the past researches show a positive link between quality of information and firm success. Information is found to be important for making a necessary decision which may impact future objectives of the company. Therefore, the role of the information can be regarded as the raw material for making a decision. The use of management information system is considered to be essential when there is a great deal of information available for managers. Therefore, decision support systems simplify the way managers reach an important decision by helping them to choose the most suitable information among many alternatives. Thus, it can be mentioned that decision support systems are known as the asset of the company. The importance of decision support system becomes more important while making complex decisions. Decision support systems are believed to increase the effectiveness of complex decision-making.

H1a: The use of MIS positively influences impact on problem definition in the decision support process

After obtaining relevant information on internal and external forces, management information systems are used to find problems pertaining to the success of the firm. In other words, decision support process is enhanced in terms of problem identification with the contribution of management information system. Most scholars argued about the speed of problem identification. That is to say, many studies found a positive relationship between the speed of problem identification and management information systems focusing on the accelerating role of management information systems. Therefore, Marchland (2003) mentioned the positive correlation between the management information system and speed of problem identification mentioning that role of MIS is significant in forecasting marketing trends, shifts, competition and changes in both internal and external environmental forces. Decision support systems have been widely discussed and analyzed in the literature for the long period of time. Traditionally, decision support systems were described in relation to their role of obtaining and analyzing the information. This type of information was later used for decision-making purposes. However, the evolution of new information technologies has enabled to problem identification and storage as well as later usage of information which contributed positively to the operation of decision support systems. Moreover, some additional function of decision support systems such as risk identification and risk assessment has been identified. Decision support systems are reported to have different benefits. For example, Decision support systems can handle a large amount of data for decision-making purposes. Moreover, DSS can be utilized in order to collect data from existing internal and external sources. DSS also knew for presenting reports in order to meet the managers and organization's needs. Using the specific software packages, the management information systems can conduct complex and specific analysis and comparisons. MIS is also believed to provide the flexibility for managers while they make important decisions. Information systems, particularly, management information systems are reported to be used in almost all organizations. Rather than storing just data, decision support system can help organizations to make better decisions.

HIb: The use of MIS positively influences speed of problem identification in the decision support process.

The developing trends of technology have completely transformed the way companies do business. Most of the business managers consider computers as an important productivity tool which can be used in their daily activities. Besides that, the importance of computer-based information systems used to make decisions, decision support systems, are gaining increasing popularity as one of the unique sides of businesses. This essay is going to provide some arguments in order to support the popular view which states that DSS is important to the dimension of firms which helps them to gain competitive advantage. Gaining competitive advantage is crucial for every business as it may lead to better firm performance through increasing sales and increasing market share. Mintzberg found three important phases of decision-making model and they consist of identification, development, and selection. While problem definition and identification are considered as the phases under identification, the decision-making analysis can be described with relation to the activities of the development phase of decision-making model. Precisely, development stage of decision making identified by Mintzberg can be divided into two phases. The first phase, known as "search" phase is involved in finding and offering solutions for the problems identified in 
"identification" stage of the model. The second stage of development phases is regarded as "design" phase, where the proposed solution are adjusted to the context of identified problems or if they are not fit, additional solutions are to be proposed. Management information system can help managers to find a necessary solution for the given problems since problem identification and decision-making analysis is an important to function of decision support systems. Therefore, management information system is crucial in grouping different sort of information into relevant phases and create good sources of information which can be useful for decision-making purposes. Decision-making analysis is considered as a complex process. Evolution of decision support systems can significantly reduce the burden of making decisions simplifying the daily work of top level managers.

H2: The use of MIS positively influences decision-making analysis in the decision support process.

The last stage of decision-making model proposed by Mintzberg involves selection phase. Selection phase is also considered to be important in supporting the decision support systems. This stage begins with checking the available information which may be used to reach a specific conclusion. The rest of the information which is irrelevant in this case is eliminated from the database of the system. In order to select only relevant information for decision-making purposes, the evaluation-choice function is processed. After selecting information, "authorization" function is processed with the presence of individual who is responsible for choosing the right information which may fit firm-specific objectives and goals. The main focus of selection phase can be characterized with choosing the right information in a best possible the shortest time. Conducting this operation in the best shortest time possible can be beneficial for organizations to efficiently allocate employee skills and resources into further operational purposes which are likely to increase their efficiency. Therefore, management information systems properly identifies, manages, stores and selects the necessary type of information for decision-making purposes for managers when they are in need of making necessary decision. Most scholars focus on the benefit of management information systems by mentioning the reduced time while looking for specific information as the main advantage. Therefore, it can be hypnotized that management information systems positively impacts on decision quality in the decision support systems through the help of selection phase. Moreover, it can be mentioned that selection process also contributes to the decision speed which is achieved through reduced time. Therefore, the following hypotheses are proposed:

H3a: The use of MIS positively influences decision quality in the decision support process.

DSS is regarded as one of the core competencies of businesses. Most of the business relies on DSS considering it firm's one of the important differentiated points over their competitors. Achieving right strategy involves consideration of Porter's generic strategies which include cost leadership, differentiation and cost focus and cost differentiation. Cost leadership involves acquiring larger market share through decreasing costs whereas differentiation strategy is characterized by the unique value of the product that cannot be easily observed in rivals. The last strategy including cost focus and differentiation focus involves targeting a specific niche of the market and formulating strategy based on cost leadership and differentiation. Utilization of these strategies is crucial in achieving a comparative advantage. Therefore, proper application of information system in the activities of a business can lead to better firm performance, especially in the long run. For example, the effective usage of DSS can provide expected outcomes when firm uses cost leadership strategy. For the recent years, the importance of automated management information systems has become important than ever before. Many scholars hold the view that automated management information systems lead to the revolution of decision-making process. In this regard, it can be stated that due to the increasing usage of management information systems companies are not required to rely on their employees on a constant basis. Employee duties can also be carried out thanks to the help of technologies (Jarboe, 2005). Mainly managers who are required to make decisions on constant basis benefit from the implementation of management information systems which will enhance their decision support capabilities. Moreover, by using management information systems decision maker can be sure to check whether their decisions fit organizational objectives which are a crucial part of every business. This, in turn, ensures that business activities are carried out according to the well balanced and right types of decisions (Allen, et al., 2010). Therefore, the following hypotheses are proposed:

H3b: The use of MIS positively influences decision speed in the decision support process.

The role of the decision maker is considered to be crucial in decision support systems, with a particular focus on management information system. Previous literature suggests that management information systems can positively influence employee satisfaction including its wellbeing. As it was mentioned, one of the advantages of management information systems results in the reduced time to find necessary information which increases employee efficiency. The automated process of information gathering, identification, storing and managing allows employees to increase their efficiency and leads to employee satisfaction. The positive relationship has been found between high quality of information and decision makers' satisfaction (Landrum, 2008). Another study by Wu \&Wang (2006) provided evidence for supporting the positive relationship between information quality and user satisfaction. Management information system is reported to predict user satisfaction given high quality of information (Livari, 2005).Therefore, the following hypothesis is proposed:

H4: The use of MIS positively influences decision maker's satisfaction in the decision support process.

Information content quality is important in reaching crucial decisions in the operations of decision support systems. The effective usage of management information systems is dependent on the quality content of the information. Many studies have reported that information content quality is crucial in ensuring 
the right flow of selection phase. The high quality of content decreases the amount of time which decision makers use in order to choose the right type of information which may be relevant to solve identified problems. The positive relationship has been found between high quality of information and decision makers satisfaction (Landrum, 2008). Another study by Wu \&Wang (2006) provided evidence for supporting the positive relationship between information quality and user satisfaction. Management information system is reported to predict user satisfaction given high quality of information (Livari, 2005). Many studies also found a positive relationship between information quality and user satisfaction (Halawi, 2008). Information quality is reported to influence the decision made by managers and business executives. The research found that quality of the made decision is positively related to the quality of information available at the time of decision making. Management information systems are beneficial in terms of providing the right type of the information at the right time in order to make a decision. Increase in information quality implies the increase of quality of decisions (Bharati \& Chaudhury, 2004). Therefore, the following hypothesis is proposed:

H5: Information content quality has a moderating effect on the relationship between MIS use and decision support capabilities.

Information for decision-making purposes is reported to be available from internal and external sources (Livari, 2005). In this regards, most scholars pay considerable attention to the information access quality. The relative content quality of information is believed to be dependent on information access quality as well (Halawi, 2008). Marketing information systems can be used in order to provide high-quality content information for the operations of management information system as well besides primary and secondary sources of data.

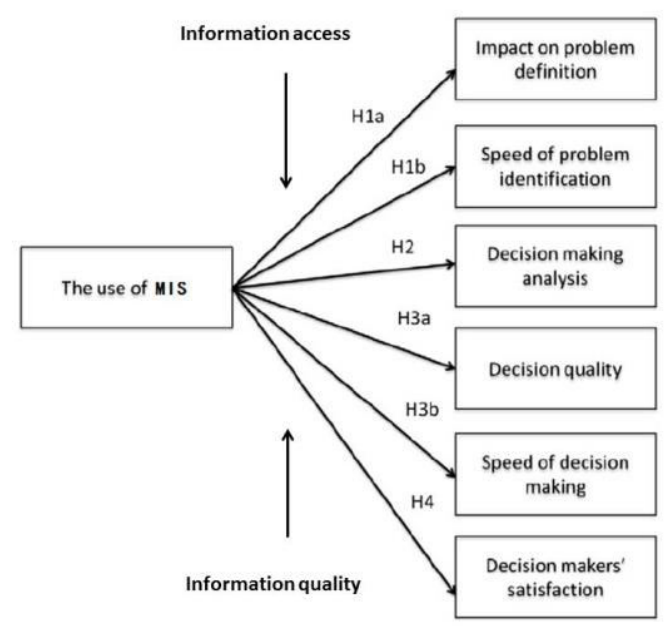

Figure 1: Research model

The following study hypothesizes a relation between information access quality to play a moderating role between management information system and decision support capabilities. Management information system is reported to collect data from both internal and external sources by simplifying the daily duties of managers. Also, as a result of information access quality management information systems offer greater responsibility for managers while making decisions. Mainly managers who are required to make decisions on constant basis benefit from the implementation of management information systems which will enhance their decision support capabilities. Moreover, by using management information systems decision maker can be sure to check whether their decisions fit organizational objectives which are a crucial part of every business.

H6: Information access quality has a moderating effect on the relationship between MIS use and decision support capabilities.

\section{Discussion and Implications}

Most of the past researches show a positive link between quality of information and firm success. Information is found to be important for making a necessary decision, which may impact future objectives of the company. Therefore, the role of the information can be regarded as the raw material for making a decision. The use of management information system is considered to be essential when there is a great deal of information available for managers. Therefore, decision support systems simplify the way managers reach an important decision by helping them to choose the most suitable information among many alternatives. Thus, it can be mentioned that decision support systems are known as the asset of the company. Traditionally, decision support systems were described in relation to their role in obtaining and analyzing the information. This type of information was later used for decision-making purposes. However, the evolution of new information technologies has enabled to problem identification and storage as well as later usage of information, which contributed positively to the operation of decision support systems. Moreover, some additional function of decision support systems such as risk identification and risk assessment has been identified. Management information system can help managers to find a necessary solution for the given problems since problem identification and decision-making analysis is an important to function of decision support systems (Mohammed A, and $\mathrm{Hu}, \mathrm{W}$, 2015; Ghazi A and $\mathrm{Hu}, \mathrm{W}, 2015)$. Therefore, management information system is crucial in grouping different sort of information into relevant phases and create good sources of information which can be useful for decision-making purposes. Mainly managers who are required to make decisions on constant basis benefit from the implementation of management information systems, which will enhance their decision, support capabilities. Moreover, by using management information systems decision maker can be sure to check whether their decisions fit organizational objectives, which are a crucial part of every business. This, in turn, ensures that business activities are carried out according to the well-balanced and right types of decisions. The practical implications of the current research should be taken into consideration by all business executives and managers who are faced with the challenges of decision making on a constant basis. Considering the increasing popularity of management information systems in decision support systems, this study is beneficial in terms of paying attention to the 
importance of problem identification, its speed, and quality. The variables used in this research were formulated based on the previous research. Therefore, it is crucial to consider the importance of other variables such as competitive advantage that can be used to explain the relationship between management information system and decision support systems.

\section{Conclusion}

Management information systems are reported to be beneficial for the operations of the company from different perspectives. One of the obvious benefits of management information systems is observed in terms of their contribution in decision-making process. Many studies have discovered positive relationship while analyzing the impact of management information systems in decision-making process. Management information systems are believed to foster the process of decision-making capabilities. The review of the previous literature shows the evidence of various studies in support of management of information systems in contributing to the role of decision-making capabilities. However, most of the paper lacks in identifying the critical importance of information speed and its quality in supporting the role of decision-making capabilities. Particularly, the identification of problem and analysis of the problem in facilitating the role management information systems have not been studied largely. Moreover, the decision maker's satisfaction and content of information and information access quality have not been critically analyzed and studied. Thus, following the methodology of the previous studies and identifying necessary variables the current study aims to analyze the influence of management information systems in decision support capabilities.

\section{References}

- Bharati, P., \& Chaudhury, A. (2004).An empirical investigation of decision making satisfaction in webbased decision supports systems. Decision Support Systems, 37 (2), 187-197, CrossRef

- Ghazi A and Hu, W (2015) Impact of individual decision-making styles on marketing information system based decision-making International Journal of Innovation and Economic Development1(2), p. 40-49

- Halawi, A., Mccarthy, P. L., \& Aronson, E. J. (2008). An Empirical Investigation of Knowledge Management System's Success. Journal of Computer Information Systems, 48 (2), 121-135

- $\quad$ Landrum, H. T., Prybutok, V. R., Strutton, D., \& Zhang, X. (2008). Examining the Merits of usefulness versus use in an information service Quality and information system success Web-based Model. Information Resources Management Journal, 21 (2), CrossRef

- Lee, J., and Myers, D., (2004) Dominant actors, political agendas, and strategic shifts over time: a Critical ethnography of an enterprise systems implementation, The Journal of Strategic Information Systems, 13(4) 355-374.
- Livari, J. (2005). An empirical test of the DeLoneMcLean model of information system success. ACM SIGMIS Database, 36 (2), 8-27.

- Marchand, D., Kettinger, J., Rollins, D. (2000) Information orientation: people, technology and the bottom line, Sloan Management Review, 41(4) 69-80.

- $\quad$ Mintzberg, H., and Raisinghani, A.(1976). The structure of "unstructured" decision processes, Administrative Science Quarterly, (1976) 246-275.

- Mohammed A, and Hu, W (2015) Using Management Information Systems (MIS) to Boost Corporate Performance International Journal of Management Science and Business Administration , 11(1), , p 55 61

- Wu, J., \& Wang, Y. (2006).Measuring KMS success: A respecification of the DeLone and McLean's model. Information \& Management, 43 (6), 728- 739, CrossRef 